\title{
Superficial pharyngeal cancer can be diagnosed in the West
}

A 51-year-old man with a history of heavy alcohol and tobacco use presented with globus sensation. Esophagogastroduodenoscopy demonstrated a 6-mm patch of reddish mucosa in the left pyriform sinus (৫ Fig. 1). The lesion was visualized most clearly using narrow-band imaging (NBI) ( $\bullet$ Fig. 2). Biopsy revealed squamous cell carcinoma in situ. The patient therefore underwent an endoscopic mucosal resection using cap (EMR-C) under general anesthesia ( Video 1 ). The procedure was well tolerated. The en-bloc resection specimen was pinned and examined using white light and Lugol's solution to assess the resection margin ( Fig. 3 ). The histopathology of the oriented resection specimen confirmed squamous cell carcinoma in situ ( Fig. 4). Because carcinoma in situ in the hypopharynx can metastasize, the patient had a positron emission tomography (PET) scan, which revealed a hypermetabolic lung lesion ( Fig. 5). He underwent video-assisted thorascopic surgery, left upper lobectomy, and removal of a 1.5-cm adenocarcinoma.

Muto et al. have described the utility of careful endoscopy of the hypopharynx, especially in those at high risk for development of head and neck cancers [1]. Early diagnosis offers the best chance of survival from these cancers, which historically have poor prognosis. With the use of image-enhanced endoscopy (IEE) and $\mathrm{NBI}$, the increased density, size, and shape of the surface microvasculature of squamous cell cancers causes the lesions to appear as a brown area with a sharp border on the background of greenish mucosa. Application of Lugol's solution is useful to delineate the border. We safely applied minimally invasive EMR to remove this early stage pharyngeal cancer [2]. Our Japanese colleagues, who previously led us to detect the prevalence of flat and depressed colorectal neoplasms in our American population, have now also pointed us towards the diagnosis and treatment of superficial pharyngeal

\section{Video 1}

Endoscopic mucosal resection of superficial

pharyngeal cancer.

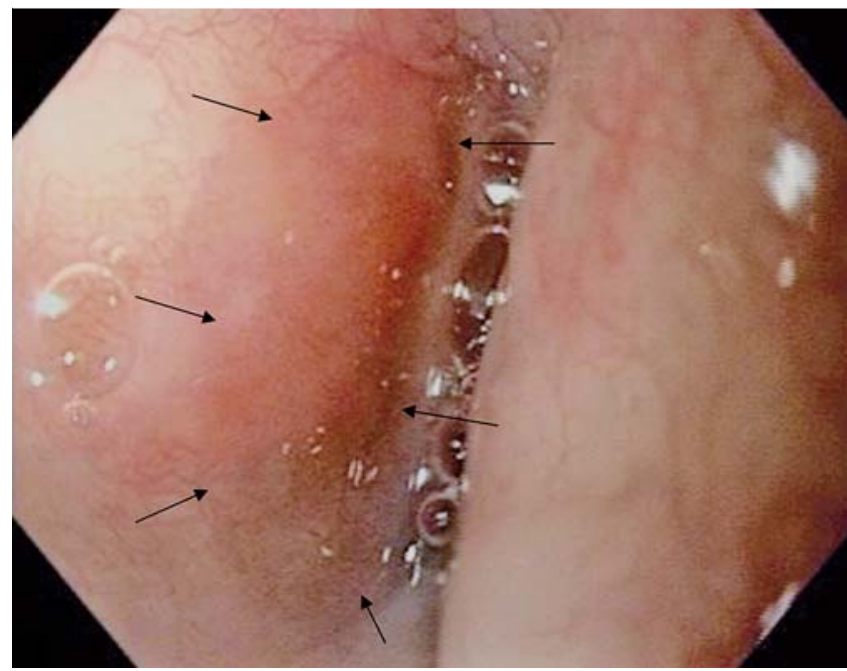

Fig. 1 Endoscopic view using white light of an area of irregularity in the left pyriform sinus.

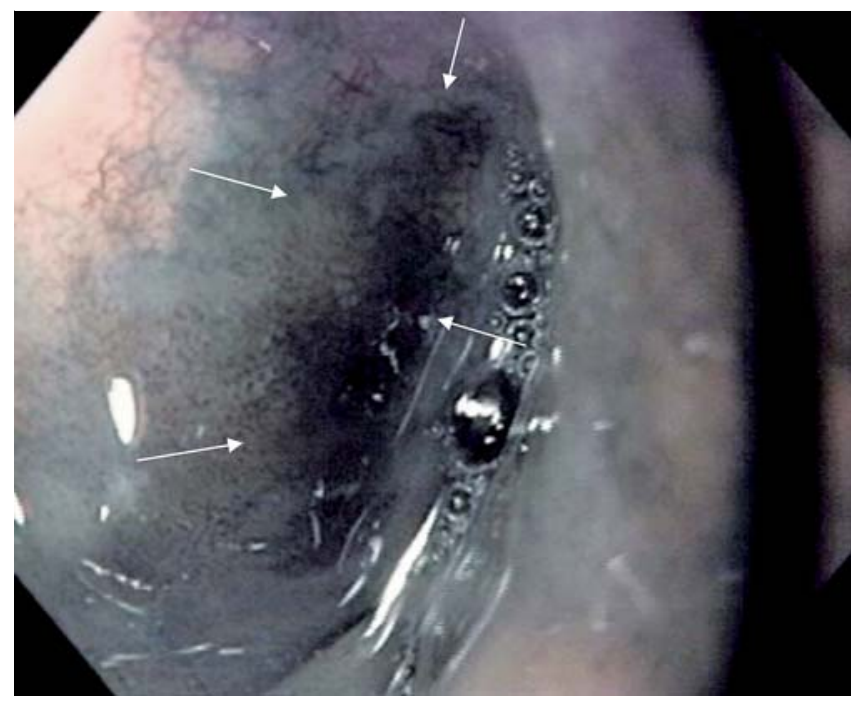

Fig. 2 Narrow-band imaging demonstrating irregular capillary loops within the area of concern.
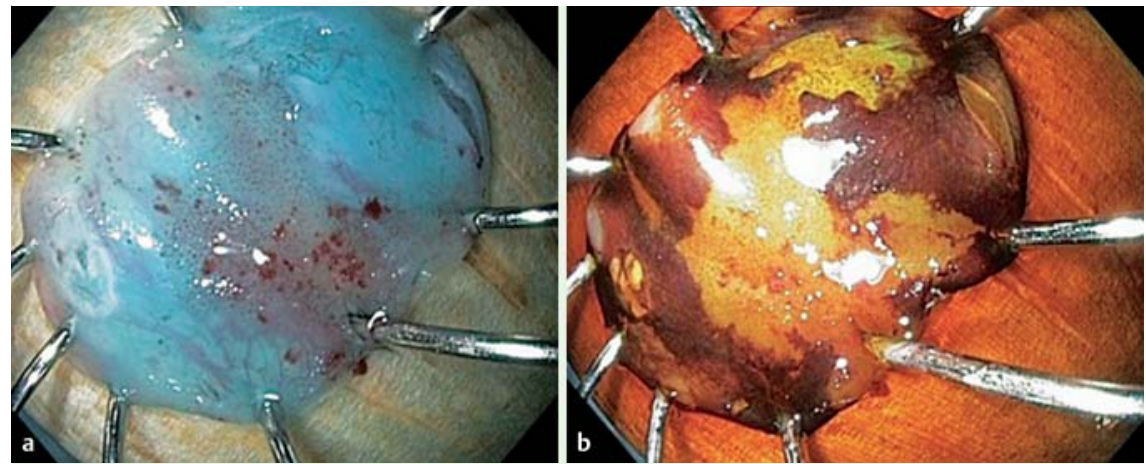

Fig. 3 The lesion, removed en-bloc by endoscopic mucosal resection using cap (EMR-C), was examined with white light (a) and Lugol's solution (b) to assess the lateral resection margin. 


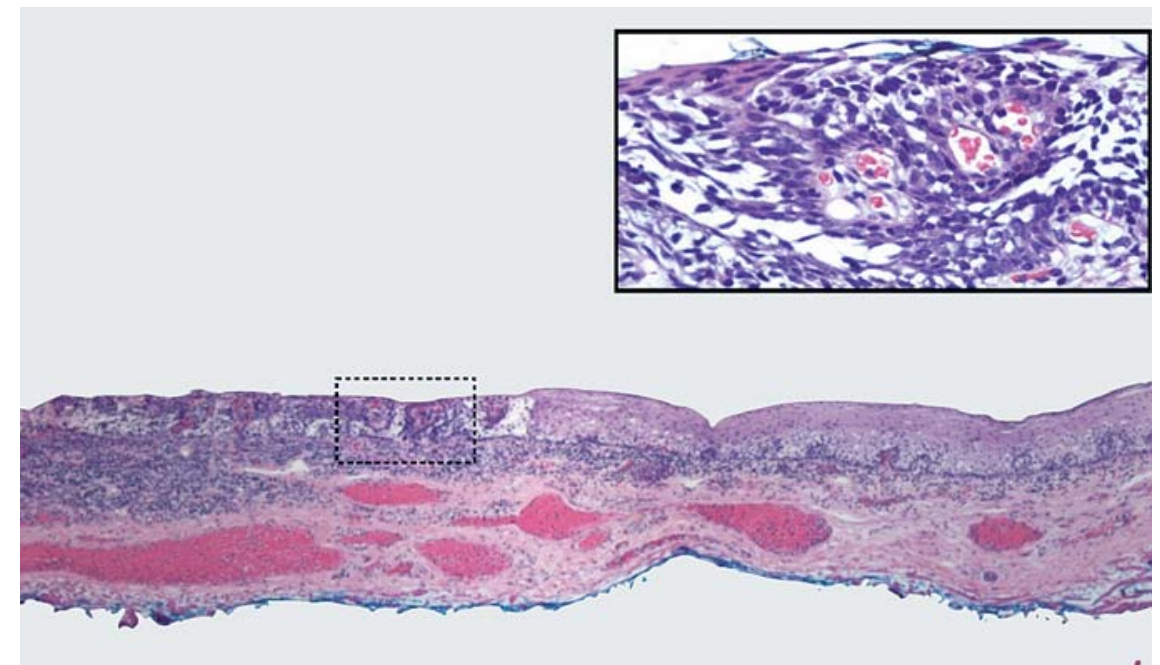

Fig. 4 Histopathologic examination of the resected specimen showed squamous carcinoma involving the deep mucosal layer, with clear lateral and vertical margins, and without lymphovascular involvement.

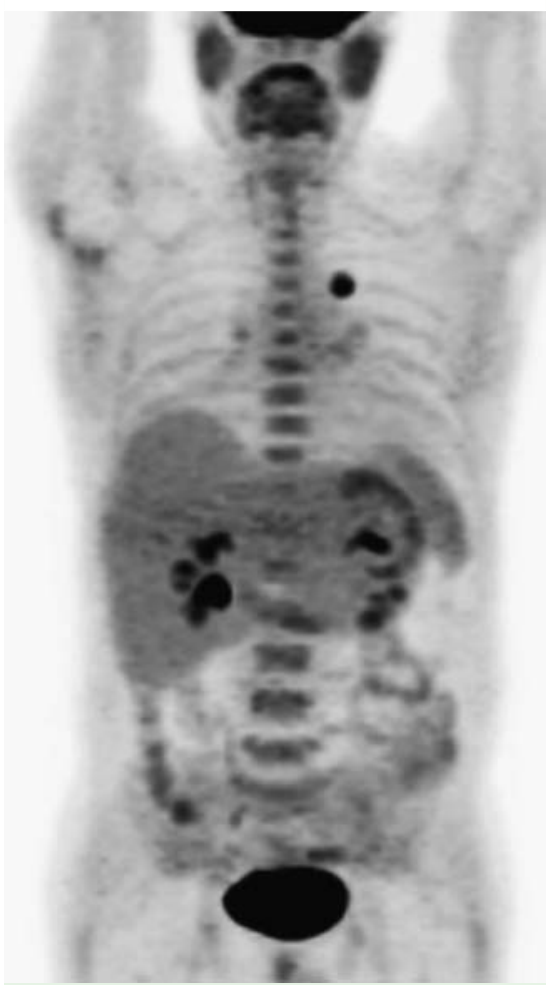

cancers [3]. We demonstrate that superficial pharyngeal cancer in an at-risk patient can be detected with white light and enhanced endoscopy and resected using mucosal resection in our Western population.

\section{Endoscopy_UCTN_Code_CCL_1AB_2AB}

\section{Competing interests: None}

\section{S. Mou ${ }^{1}$, T. Kaltenbach ${ }^{1}$, M. Yao ${ }^{2}$,}

\section{R. Soetikno²}

1 VA Palo Alto and Stanford University School of Medicine, Department of Medicine, Division of Gastroenterology, Palo Alto, California, USA

2 VA Palo Alto and Stanford University School of Medicine, Department of Surgery, Division of Otolaryngology, Palo Alto, California, USA

\section{References}

1 Muto M, Minashi K, Yano T et al. Early detection of superficial squamous cell carcinoma in the head and neck region and esophagus by narrow band imaging: a multicenter randomized controlled trial. J Clin Oncol 2010; 28: $1566-1572$

2 Suzuki H, Saito Y, Oda S et al. Feasibility of endoscopic mucosal resection for superficial pharyngeal cancer: a minimally invasive treatment. Endoscopy 2010; 42: 1 - 7

3 Soetikno RM, Kaltenbach T, Rouse RV et al. Prevalence of nonpolypoid (flat and depressed) colorectal neoplasms in asymptomatic and symptomatic adults. JAMA 2008; 299: 1027-1035

\section{Bibliography}

DOI $10.1055 / \mathrm{s}-0030-1256419$

Endoscopy 2011; 43: E248 -E249

(c) Georg Thieme Verlag KG Stuttgart · New York . ISSN 0013-726X

\section{Corresponding author}

\section{R. Soetikno, MD}

Chief of Endoscopy, VA Palo Alto

Clinical Professor (Affiliated) of Medicine,

Stanford University

3801 Miranda Avenue Gl=111

Palo Alto

CA 94304, USA

Fax: +1-650-849-0255

soetikno@earthlink.net
Fig. 5 Positron emission tomography (PET) scan demonstrating a hypermetabolic lung nodule that was ultimately diagnosed as adenocarcinoma. 